\title{
ARTICLE
}

Clinical Research

\section{Survival of African-American and Caucasian men after sipuleucel-T immunotherapy: outcomes from the PROCEED registry}

\author{
Oliver Sartor ${ }^{1} \cdot$ Andrew J. Armstrong $\mathbb{D}^{2} \cdot$ Chiledum Ahaghotu ${ }^{3} \cdot$ David G. McLeod $^{4,5} \cdot$ Matthew R. Cooperberg $\mathbb{D}^{6} \cdot$ \\ David F. Penson ${ }^{7}$. Philip W. Kantoff ${ }^{8} \cdot$ Nicholas J. Vogelzang $^{9} \cdot$ Arif Hussain $^{10} \cdot$ Christopher M. Pieczonka $^{11}$. \\ Neal D. Shore ${ }^{12}$ - David I. Quinn ${ }^{13}$. Eric J. Small ${ }^{14}$ Elisabeth I. Heath ${ }^{15} \cdot$ Ronald F. Tutrone $^{16}$. \\ Paul F. Schellhammer ${ }^{17}$. Matthew Harmon ${ }^{18}$. Nancy N. Chang ${ }^{18} \cdot$ Nadeem A. Sheikh $^{18} \cdot$ Bruce Brown $^{18}$. \\ Stephen J. Freedland ${ }^{19,20} \cdot$ Celestia S. Higano $^{21}$
}

Received: 30 October 2019 / Revised: 29 January 2020 / Accepted: 11 February 2020 / Published online: 28 February 2020

(c) The Author(s) 2020. This article is published with open access

\begin{abstract}
Purpose African Americans experience greater prostate cancer risk and mortality than do Caucasians. An analysis of pooled phase III data suggested differences in overall survival (OS) between African American and Caucasian men receiving sipuleucel-T. We explored this in PROCEED (NCT01306890), an FDA-requested registry in over 1900 patients with metastatic castration-resistant prostate cancer (mCRPC) treated with sipuleucel-T.

Patients and methods OS for patients who received $\geq 1$ sipuleucel-T infusion was compared between African American and Caucasian men using an all patient set and a baseline prostate-specific antigen (PSA)-matched set (two Caucasians to every one African American with baseline PSAs within 10\% of each other). Univariable and multivariable analyses were conducted. Survival data were examined using Kaplan-Meier and Cox proportional hazard methodologies.

Results Median follow-up was 46.6 months. Overall survival differed between African American and Caucasian men with hazard ratios (HR) of 0.81 (95\% confidence interval [CI]: $0.68-0.97, P=0.03)$ in the all patient set and $0.70(95 \% \mathrm{CI}$ : 0.57-0.86, $P<0.001)$ in the PSA-matched set. Median OS was longer in African Americans than in Caucasian men for both analysis sets, e.g., 35.3 and 25.8 months, respectively, in the PSA-matched set. Similar results were observed in the all patient set. Differences were larger when treatment began at lower baseline PSA; curves were more similar among patients with higher baseline PSA. In patients with baseline PSA below the median, the HR was 0.52 (95\% CI: 0.37-0.72, $P<0.001$ ), with median OS of 54.3 versus 33.4 months. Known prognostic factors and African American race (multivariable analyses; HR: $0.60,95 \%$ CI: $0.48-0.74, P<0.001$ ) were independently associated with OS. Use of post-sipuleucel$\mathrm{T}$ anticancer interventions was balanced between races.

Conclusion In this exploratory analysis of a registry including nearly $12 \%$ African American men with mCRPC, OS was significantly different between African Americans and Caucasians, indicating further research is warranted.
\end{abstract}

These authors were joint lead authors and contributed equally as such: Oliver Sartor, Andrew J. Armstrong

These authors were joint senior authors and contributed equally as such: Stephen J. Freedland, Celestia S. Higano

Supplementary information The online version of this article (https:// doi.org/10.1038/s41391-020-0213-7) contains supplementary material, which is available to authorized users.

Oliver Sartor

osartor@tulane.edu

Extended author information available on the last page of the article

\section{Introduction}

Sipuleucel-T, an established autologous cellular immunotherapy for men with asymptomatic/minimally symptomatic metastatic castration-resistant prostate cancer (mCRPC), is recommended as an initial option for treatment by the National Comprehensive Cancer Network Clinical Practice Guidelines in Oncology for Prostate Cancer based on category 1 evidence [1]. Sipuleucel-T improved median overall survival (OS) by 4.1 months versus placebo in the pivotal IMPACT trial (NCT00065442), with a separate post hoc analysis demonstrating a 13-month OS benefit in those with prostate-specific antigen (PSA) levels below the median of $22.1 \mathrm{ng} / \mathrm{mL}$ at 
treatment start $[2,3]$. In a contemporary real-world setting of care, data from the PROVENGE Registry for the Observation, Collection, and Evaluation of Experience Data (PROCEED; NCT01306890) found that mCRPC patients treated with sipuleucel-T had a median OS of 30.7 months; with a median follow-up of 46.6 months and an OS of 47.7 months $(95 \%$ confidence interval $[\mathrm{CI}], 43.5-50.7$ months) in the lowest baseline PSA quartile $(\leq 5.27 \mathrm{ng} / \mathrm{mL})$ [4].

Racial differences in the natural history of prostate cancer and responses to treatments have been described previously; several reviews have discussed different aspects [5-8]. These studies have described differences in biology, access-to-care, socioeconomics, and treatment as well as relative participation in clinical trials [8]. Observed biologic differences include differences within the tumor microenvironment, gene expression, and immunologic pathways [9-14]. Clinically, risk, metastasis rates, and mortality with prostate cancer are higher in African Americans versus Caucasians [15-17].

Yet, several datasets suggest African Americans may have better outcomes with some prostate cancer treatments. A pooled retrospective analysis of eight multicenter trials in "hormone-refractory" prostate cancer showed that black men had significantly lower risk for death than white men [18]. This was recently confirmed by a pooled clinical trial analysis of docetaxel-treated mCRPC men and in a trial of radium-223 [19, 20]. A poster presented at the Genitourinary Symposium in 2019 reported similar observations with enzalutamide and abiraterone acetate [21]. These highlight the importance of understanding race-specific differences to optimize therapy recommendations and the need to overcome the chronic underrepresentation of African American patients in clinical trials.

A retrospective analysis of the clinical trials of sipuleucel$\mathrm{T}$ found a relatively small number of African Americans ( $n=43,5.5 \%$ of all) enrolled across the three phase III mCRPC studies for sipuleucel-T (including IMPACT [NCT00065442], D9901 [NCT00005947], and D9902A [NCT01133704]). Yet, among these sipuleucel-T-treated African American patients, a 30.7-month OS benefit with sipuleucel-T versus placebo (HR, 0.29; 95\% CI, 0.13-0.66, $P=0.003$ ) was observed, a primarily hypothesis-generating observation given its post hoc nature and the small number of patients [22-24]. Race was also found to be an independent predictor of OS in the PROCEED registry of sipuleucel-T (HR: 1.64; 95\% CI, 1.30-2.06, $P<0.001$ ) [4].

To further explore this observed OS benefit, we performed exploratory analyses of data from the PROCEED registry, hypothesizing that African American sipuleucel-Ttreated mCRPC patients would have longer OS than their sipuleucel-T-treated Caucasian counterparts.

\section{Patients and methods}

\section{Patients and treatment}

PROCEED was a multicenter, open-label, observational registry in $\mathrm{mCRPC}$ patients who received sipuleucel-T, whose primary outcomes have been described previously [4]. Patients were treated at academic and community sites in urology and oncology clinics, from January 27, 2011 to January 17, 2017 [25]. Database lock was May 3, 2017.

Eligible men had to be at least 18 years old with advanced prostate cancer for whom sipuleucel-T treatment was indicated. They could have been enrolled either prospectively before receiving sipuleucel-T or "retrospectively," defined as "within 6 months after the first leukapheresis." Race was self-identified as Caucasian, Black or African American, Asian, Native Hawaiian or Other Pacific Islander, or American Indian or Alaska Native.

Sample size (described previously) was chosen to address the primary registry endpoint, which was to assess the cerebrovascular event (CVE) rate [4]. Originally set at 1500 patients it was later increased to 1900 to allow for 4500 person-years of follow-up provided the observed CVE incidence rate was $<2.8$ per 100 patient-years [4].

Both protocol and amendment were approved by each center's Institutional Review Board before patient enrollment. Before participation, patients provided written informed consent.

Patients received $\leq 3$ biweekly sipuleucel-T infusions. Sipuleucel-T production has been previously described [26].

\section{Objectives}

The objectives of the analyses presented here are to explore the observations of a difference in survival outcomes between races given the identification of race as an important factor in the multivariate analysis model presented in the primary paper [4], which further describes the outcomes related to the prespecified study objectives of quantifying both the risk of CVEs and survival in all subjects.

\section{Efficacy}

OS was measured from the first sipuleucel-T infusion until date of death as reported by site investigator. Patients were followed for $\geq 3$ years, until death or study withdrawal, or study close. In the few cases where death could not be ascertained, the patient was censored at the date of the last site contact.

Secondarily, the study explored efficacy in terms of race. As part of an exploratory objective, the number and types of 
OS-prolonging anticancer interventions (ACIs) postsipuleucel-T were also analyzed.

\section{Safety}

Safety in PROCEED was assessed by recording serious adverse events (SAEs) using MedDRA version 19.1 (for greater details, please see Higano et al.) [4].

\section{Data analyses}

Effect of race on OS in patients treated with sipuleucel-T was assessed by comparing first the subset of all African American and Caucasian men and then the subset of baseline PSA-matched African American and Caucasian men. Previously, baseline PSA level was identified as the strongest predictor of post-sipuleucel-T OS [3], and baseline PSA levels were significantly different between African American and Caucasian patients in PROCEED $(P<0.001)$ [4]. Thus, Caucasian subjects were matched (2:1) to African American subjects with baseline PSA levels within $\pm 10 \%$ of the Caucasian baseline PSA value to minimize the effect of this clinical imbalance on survival. For these PSA-matched cohorts, OS by baseline median PSA levels, PSA quartiles, and post-sipuleucel-T receipt of OS-prolonging ACIs (abiraterone, enzalutamide, docetaxel, cabazitaxel, or radium-223) in mCRPC were assessed using univariable and multivariable analysis (MVA).

OS data were analyzed using Kaplan-Meier methodology, while HRs and 95\% CIs were obtained using Cox proportional hazards regression. $P$ values were not adjusted for multiplicity as this was an exploratory analysis. Univariable analysis, stepwise Cox modeling, and MVA, with imputation of missing data, were conducted to assess for independent baseline predictors of survival that had both clinical and statistical relevance.

Multiple imputation and statistical analysis were performed using SAS 9.4 and SAS/STAT 14.2 (SAS Institute, Cary NC). In imputing missing data, the Markov Chain Monte Carlo method was used, and all imputations had 15 iterations.

\section{Results}

Median follow-up was 46.6 months. During the follow-up period of $>4$ years, 1255 patients died; 964 (76.8\%) due to prostate cancer progression.

\section{Patients}

Of 1976 patients enrolled, 1902 received $\geq 1$ sipuleucel-T infusion (1649 Caucasians, 221 African Americans,
32 of other race; Supplementary Table S1; disposition, Supplementary Figs. S1, S2). Most patients were treated in oncology practices $(1248,66 \%)$, while $654(34 \%)$ patients were treated in urology practices. Most patients (79\%) were treated with sipuleucel-T at 140 community clinics, while the remainder were treated at 52 academic centers.

Across all patients, baseline PSA was notably higher in African American patients (33.0 versus $13.9 \mathrm{ng} / \mathrm{mL}$ in Caucasians). African Americans exhibited lower hemoglobin, longer time from diagnosis to sipuleucel-T treatment, and lower likelihood of having had prior chemotherapy, regardless of whether looking at the overall population or PSA-matched cohorts (Table 1). Two African Americans were excluded in the PSA-matching process: one lacked a baseline PSA, and another had a high PSA value that could not be matched within $\pm 10 \%$ to any Caucasian patient (Supplementary Fig. S1).

\section{Overall survival}

Overall survival differed between African American and Caucasian men with a HR of 0.70 (95\% CI: $0.57-0.86, P<$ $0.001)$ in the PSA-matched set and 0.81 (95\% CI: $0.68-0.97, P=0.03$ ) in the all patient set (Fig. 1, Supplemental Figures S1 and S2). Median OS was longer in African Americans than in Caucasian men for both analysis sets (Fig. 1, Supplementary Figs. S1, S2, Table 2). In the PSA-matched set, median OS was 35.3 and 25.8 months, respectively (Table 2). The results for the all patient set were similar: 35.2 and 29.9 months, respectively.

Baseline PSA impacted survival outcomes, with men with lower baseline PSA exhibiting longer OS (Table 2). Differences between African Americans and Caucasians were statistically significant at lower baseline PSAs, but not at higher baseline PSAs (Table 2); for example, among men with baseline PSA less than the population median, the HR was $0.52(95 \% \mathrm{CI}, 0.37-0.72, P<0.001)$ in the PSA-matched set.

Univariable analyses (Supplementary Table S2) within the PSA-matched set of sipuleucel-T-treated African Americans and Caucasians demonstrated that 12 of the 18 evaluated baseline characteristics were statistically significant in their association with OS, including age, body weight, ethnicity, Eastern Cooperative Oncology Group performance status, PSA, alkaline phosphatase, hemoglobin, lactate dehydrogenase (LDH), lymph node only metastases, prior prostatectomy, prior abiraterone/enzalutamide, and prior docetaxel/cabazitaxel. All but LDH were included in the final primary MVA. LDH was excluded because the amount of missing data was too extensive for data imputation. The resultant final primary multivariable analysis demonstrated that, after adjusting 
Table 1 Demographics and baseline disease characteristics for the Subset of PSA-matched African American and Caucasian patients with mCRPC who were treated with sipuleucel-T in PROCEED.

\begin{tabular}{|c|c|c|}
\hline & \multicolumn{2}{|c|}{ Sipuleucel-T-treated, PSA-matched patients } \\
\hline & $\begin{array}{l}\text { African American } \\
\text { patients }(n=219)\end{array}$ & $\begin{array}{l}\text { Caucasian patients } \\
(n=438)\end{array}$ \\
\hline Median (min-max) age, years & $71(42-94)$ & $72(48-93)$ \\
\hline \multicolumn{3}{|l|}{ ECOG PS, $n(\%)$} \\
\hline 0 & $138(63)$ & $299(68)$ \\
\hline 1 & $76(35)$ & $124(28)$ \\
\hline 2 & $3(1)$ & $14(3)$ \\
\hline 3 & $1(0.5)$ & $1(0.2)$ \\
\hline Missing & $1(0.5)$ & 0 \\
\hline \multicolumn{3}{|l|}{ Worst Gleason score sum, $n(\%)$} \\
\hline$\leq 6$ & $28(13)$ & $61(14)$ \\
\hline 7 & $65(30)$ & $135(31)$ \\
\hline$\geq 8$ & $101(46)$ & $212(48)$ \\
\hline Missing & $25(11)$ & $30(7)$ \\
\hline Median (Q1-Q3) body weight, kg & $88(79-102)$ & $90(79-101)$ \\
\hline Median (Q1-Q3) PSA, ng/mL & $32.9(8.6-89.7)$ & $28.7(7.8-82.3)$ \\
\hline$n$ & 219 & 438 \\
\hline Median (Q1-Q3) LDH, U/L & $191(170-233)$ & $188(157-220)$ \\
\hline$n$ & 69 & 165 \\
\hline Median (Q1-Q3) ALP, U/L & $88(69-115)$ & $83(64-116)$ \\
\hline$n$ & 170 & 361 \\
\hline Median (Q1-Q3) hemoglobin, g/dL & $12.1(11.0-12.9)$ & $12.9(11.9-13.7)$ \\
\hline$n$ & 210 & 417 \\
\hline $\begin{array}{l}\text { Median }(\mathrm{Q} 1-\mathrm{Q} 3) \text { time from } \\
\text { diagnosis/biopsy to first } \\
\text { infusion, years }\end{array}$ & $5.8(2.5-10.8)$ & $4.9(2.5-9.7)$ \\
\hline$n$ & 169 & 395 \\
\hline \multicolumn{3}{|l|}{ Localization of disease, $n(\%)$} \\
\hline Bone only & $137(63)$ & $270(62)$ \\
\hline Bone and lymph nodes & 37 (17) & $85(19)$ \\
\hline Bone and visceral & $5(2)$ & $8(2)$ \\
\hline Bone, lymph node and visceral & $4(2)$ & $7(2)$ \\
\hline Lymph node only & $31(14)$ & $57(13)$ \\
\hline Lymph node and visceral & $2(1)$ & $1(0.2)$ \\
\hline Visceral & $2(1)$ & $6(1)$ \\
\hline Missing & $1(0.5)$ & $4(1)$ \\
\hline \multicolumn{3}{|l|}{ Number of bone metastases, $n(\%)$} \\
\hline$n$ & 183 & 370 \\
\hline$\leq 10$ & $129(71)$ & $277(75)$ \\
\hline$>10$ & $27(15)$ & $76(21)$ \\
\hline Missing & $26(14)$ & $17(5)$ \\
\hline \multicolumn{3}{|l|}{ Prior treatment, $n(\%)$} \\
\hline Primary radiation therapy & $99(45)$ & $213(49)$ \\
\hline Radical prostatectomy & $69(32)$ & $148(34)$ \\
\hline Chemotherapy & $25(11)$ & $97(22)$ \\
\hline
\end{tabular}

See Supplementary Table S1 for the comparable table for all African Americans and Caucasian men.

$A L P$ alkaline phosphatase, ECOG PS Eastern Cooperative Oncology Group performance status, $L D H$ lactate dehydrogenase, $m C R P C$ metastatic castration-resistant prostate cancer, PSA prostate-specific antigen, $Q 1$ first quartile, $Q 3$ third quartile.

for confounders, African American race is an independent predictor of median OS after sipuleucel-T (Table 3).

In the sensitivity analysis, all ten variables that met the threshold of $P<0.1$ and had been included in the final

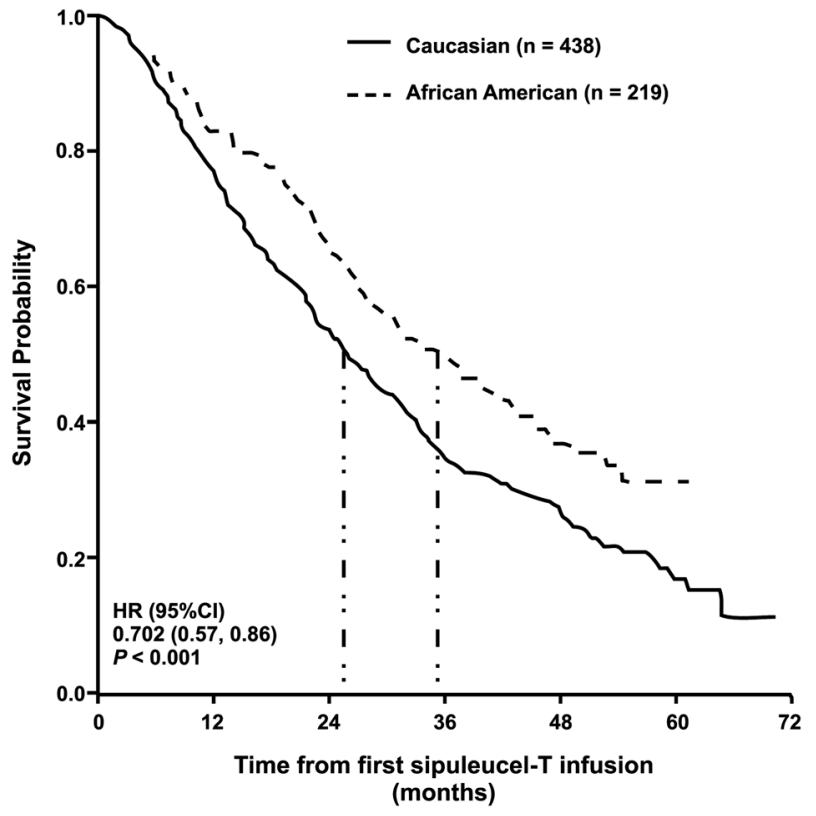

Fig. $1 \mathrm{OS}$ in the subset of PSA-matched African American and Caucasian men with mCRPC treated with sipuleucel-T in PROCEED for all included patients. Median OS estimates indicated by vertical dash-dot lines. CI confidence interval, HR hazard ratio, OS overall survival, PSA prostate-specific antigen.

stepwise multivariable model (Supplementary Table S3) were also part of the final primary MVA. One difference between the two models was that baseline body weight was excluded from the sensitivity analysis. After adjusting for confounders, African American race was again an independent predictor of OS after sipuleucel-T in this sensitivity analysis.

\section{Post-sipuleucel-T anticancer intervention}

The most commonly used survival-prolonging ACIs after sipuleucel-T were abiraterone, enzalutamide, and docetaxel for both races (Table 4). While all patients were diagnosed with mCRPC, African Americans were more likely to receive hormonal agents, while Caucasians were slightly more likely to be treated with chemotherapy (53\% African Americans and 66\% Caucasians received chemotherapy). The number of ACIs post-sipuleucel-T was balanced between the PSA-matched populations (Table 4).

\section{Safety}

SAEs occurred in 46 (21\%) African Americans treated with sipuleucel-T and 64 (14.6\%) PSA-matched sipuleucel-Ttreated Caucasians. Grade 3-5 SAEs occurred in $32(15 \%)$ African Americans and 48 (11\%) PSA-matched Caucasians. The incidence of all-grade and grade 3-5 SAEs was low and generally similar between races (Supplementary Table S4). 
Table 2 Summary of statistical analyses of OS in the subset of PSA-matched African American and Caucasian patients with mCRPC who were treated with sipuleucel-T in PROCEED.

\begin{tabular}{|c|c|c|c|c|c|}
\hline \multirow[t]{2}{*}{ Comparison } & \multicolumn{2}{|c|}{$\begin{array}{l}\text { Median OS, months for sipuleucel-T-treated, } \\
\text { PSA-matched patients } \\
\text { HR }(95 \% \mathrm{CI})^{\mathrm{a}}\end{array}$} & \multirow[t]{2}{*}{$\begin{array}{l}\text { Difference in OS, } \\
\text { months }\end{array}$} & \multirow[t]{2}{*}{$\mathrm{HR}(95 \% \mathrm{CI})^{\mathrm{b}, \mathrm{c}}$} & \multirow[t]{2}{*}{$P$ value } \\
\hline & African American & Caucasian & & & \\
\hline All patients & $35.3(28.7-42.7) n=219^{\mathrm{d}}$ & $25.8(22.6-29.0) n=438$ & 9.5 & $0.70(0.57-0.86)$ & $<0.001$ \\
\hline \multicolumn{6}{|l|}{ By median baseline PSA } \\
\hline$\leq 29.48 \mathrm{ng} / \mathrm{mL}$ & $54.3(43.0-\mathrm{NE}) n=107$ & $33.4(29.8-36.6) n=222$ & 20.9 & $0.52(0.37-0.72)$ & $<0.001$ \\
\hline$>29.48 \mathrm{ng} / \mathrm{mL}$ & $22.7(19.2-27.6) n=112$ & $17.6(14.3-22.1) n=216$ & 5.1 & $0.86(0.66-1.11)$ & 0.249 \\
\hline \multicolumn{6}{|l|}{ By baseline PSA quartile $^{\mathrm{d}}$} \\
\hline$\leq 8 \mathrm{ng} / \mathrm{mL}$ & $54.3(43.0-\mathrm{NE}) n=53$ & $37.4(31.6-47.7) n=112$ & 16.9 & $0.49(0.29-0.81)$ & 0.005 \\
\hline$>8$ to $\leq 29.48 \mathrm{ng} / \mathrm{mL}$ & $48.8(31.2-\mathrm{NE}) n=54$ & $30.9(25.0-33.4) n=110$ & 17.9 & $0.54(0.35-0.85)$ & 0.008 \\
\hline$>29.48$ to $\leq 82.4 \mathrm{ng} / \mathrm{mL}$ & $27.2(22.4-33.0) n=56$ & $22.1(17.5-25.4) n=108$ & 5.1 & $0.80(0.55-1.16)$ & 0.236 \\
\hline$>82.4 \mathrm{ng} / \mathrm{mL}$ & $16.4(10.7-25.1) n=56$ & $13.0(10.7-18.3) n=108$ & 3.4 & $0.92(0.64-1.32)$ & 0.638 \\
\hline
\end{tabular}

Almost all patients who died or left the study did so before the estimated median time in months of 54.3 months. In the group with baseline PSA $\leq 8 \mathrm{ng} / \mathrm{mL}, 18$ of the 19 patients (who experienced a death) died as of the estimated median survival time of 54.3 months. In the group with baseline PSA $>8$ to $\leq 29.48 \mathrm{ng} / \mathrm{mL}, 24$ of the 25 died as of the estimated median survival time of 48.8 months.

$C I$ confidence interval, $H R$ hazard ratio, $N E$ not evaluable, $O S$ overall survival, $P S A$ prostate-specific antigen.

${ }^{a}$ Kaplan-Meier method.

${ }^{\mathrm{b}} \mathrm{HR}<1$ indicates a better outcome in African American patients treated with sipuleucel-T versus sipuleucel-T-treated PSA-matched Caucasians. ${ }^{\mathrm{c}} \mathrm{A}$ Cox regression model with Caucasians as the reference arm.

${ }^{\text {d}}$ PROCEED enrolled 221 African Americans: two were excluded as one patient had no baseline PSA and the other had a baseline PSA of $1462 \mathrm{ng} / \mathrm{mL}$ with no matching Caucasian patients.

\section{Discussion}

In PROCEED, the largest, real-world registry with sipuleucel-T in men with $\mathrm{mCRPC}$, the percentage of enrolled African Americans was considerably higher than found in typical advanced prostate cancer trials, allowing for these exploratory analyses of the impact of race on survival to be performed. Overall survival was statistically different between African American and Caucasian men, both among the entire cohort and when examined as a PSAmatched set to correct for differences in baseline PSA between the two races (Table 2, Fig. 1). Further, median OS was longer in African Americans than in Caucasian men, regardless of analysis set (Table 2). Detailed multivariable and sensitivity analyses confirmed African American race as an independent predictor of OS with sipuleucel-T, as observed previously [4]. Importantly, variables predictive of OS identified in these analyses were consistent with prior studies.

The OS difference between African Americans and Caucasians treated with sipuleucel-T in PROCEED was more pronounced in mCRPC patients with lower baseline PSA, translating into nearly 4.5 years of survival in the lowest PSA quartile (Table 2). These real-world findings are concordant with observations from the IMPACT study [3]. SAEs did not differ between groups, and no new safety signal emerged from this real-world registry. Together, these analyses support previous findings with sipuleucel-T treatment, where while both groups exhibit a survival benefit, African American men exhibited a greater survival benefit compared with Caucasian men [22], yet it also raises questions as to the reasons why.

Reasons behind the larger representation of African Americans in the current study are unknown, given historically African Americans have been under-represented in clinical trials $[8,27]$. One contributing factor may be the time frame of the PROCEED registry (first subject first visit 27 January 2011 and last subject last visit 17 January 2017), a period of significant change in advanced prostate cancer treatment.

The clinical relevance and importance of these findings are highlighted by the fact that prostate cancer is more prevalent in African Americans and more likely to be advanced at presentation, with a greater propensity for progression and lethality, compared to Caucasians [16, 17]. Yet, the underrepresentation of African Americans in clinical trials means there is a paucity of data regarding mCRPC presentation in these two races [8].

Anecdotal evidence suggests differences in the natural history of prostate cancer and in responses to treatment in African American men compared with Caucasian men [5-17]. There are multiple reports of survival benefits with various treatments for mCRPC favoring African American men over Caucasian men [18, 19]. Prior data 
Table 3 Final primary MVA of OS in the subset of PSA-matched African American and Caucasian men with mCRPC treated with sipuleucel-T in PROCEED $(n=657)$.

\begin{tabular}{|c|c|c|}
\hline Baseline covariate & $\mathrm{HR}(95 \% \mathrm{CI})$ & $P$ value ${ }^{\mathrm{a}}$ \\
\hline $\begin{array}{l}\text { Race: African American versus } \\
\text { Caucasian }\end{array}$ & $0.60(0.48-0.74)$ & $<0.001$ \\
\hline Age: $>$ median versus $\leq$ median & $1.26(1.03-1.53)$ & 0.023 \\
\hline Body weight: $>$ median versus $\leq$ median & $0.97(0.80-1.17)$ & 0.723 \\
\hline ECOG PS: $>0$ versus 0 & $1.33(1.09-1.61)$ & 0.005 \\
\hline $\begin{array}{l}\text { Baseline PSA: >median versus } \\
\leq \text { median }\end{array}$ & $1.74(1.43-2.12)$ & $<0.001$ \\
\hline $\begin{array}{l}\text { Baseline ALP: >median versus } \\
\leq \text { median }\end{array}$ & $1.59(1.27-1.99)$ & $<0.001$ \\
\hline $\begin{array}{l}\text { Baseline hemoglobin: }>\text { median } \\
\text { versus } \leq \text { median }\end{array}$ & $0.66(0.54-0.81)$ & $<0.001$ \\
\hline $\begin{array}{l}\text { Lymph node only metastases: yes } \\
\text { versus no }\end{array}$ & $0.66(0.49-0.90)$ & 0.009 \\
\hline Prior prostatectomy: yes versus no & $0.82(0.68-1.01)$ & 0.058 \\
\hline $\begin{array}{l}\text { Prior abiraterone/enzalutamide: yes } \\
\text { versus no }\end{array}$ & $1.64(1.19-2.25)$ & 0.002 \\
\hline $\begin{array}{l}\text { Prior docetaxel/cabazitaxel: yes } \\
\text { versus no }\end{array}$ & $1.42(1.11-1.81)$ & 0.005 \\
\hline
\end{tabular}

$A L P$ alkaline phosphatase, $C I$ confidence interval, ECOG PS Eastern Cooperative Oncology Group performance status, $H R$ hazard ratio, $M V A$ multivariable analysis, $O S$ overall survival, $P S A$ prostate-specific antigen.

${ }^{a}$ Variables that were statistically significant on univariable analyses were assessed for clinical relevance and included in the final primary multivariable model if deemed both statistically and clinically significant. For multivariable Cox modeling, the Markov chain Monte Carlo imputation method was used for imputing missing data. Parameters with missing data include ECOG PS, ALP, hemoglobin, weight, prior local therapy, and lymph node only metastases. An MVA of the entire PROCEED population was not undertaken due to a major imbalance between the numbers of African American and Caucasian patients, with concern for an underpowered analysis.

suggest that African American men with mCRPC have lower risk for death versus Caucasians [18]. Halabi et al. [19] also examined pooled data from nine phase III trials with docetaxel/prednisone in patients with mCRPC in multivariable analysis adjusted for established risk factors; they observed both differences in multiple baseline patient characteristics and a survival benefit (HR: 0.81; 95\% CI, 0.72-0.91) favoring African Americans $(n=$ $500)$ versus Caucasians $(n=7528)$ [19]. This was recently confirmed in a trial of radium-223 [20]. McNamara et al. also reported better OS in response to abiraterone acetate or enzalutamide in chemotherapy naïve African American mCRPC patients [21]. These observations align with those found in the current analyses with HRs of 0.70 (95\% CI: $0.57-0.86, P<0.001)$ in the PSA-matched set and 0.81 (95\% CI: $0.68-0.97, P=0.03$ ) in the all patient set (Table 2). Together, these data suggest that African American and Caucasian men with mCRPC may respond
Table 4 Post-sipuleucel-T ACI use in the subset of PSA-matched African American and Caucasian men with mCRPC treated with sipuleucel-T in PROCEED.

Post-sipuleucel-T ACI use in sipuleucelT-treated, PSA patients

\begin{tabular}{ll}
\hline African American & Caucasian \\
patients & patients \\
$(n=219)$ & $(n=438)$
\end{tabular}

Number of post-treatment ACIs from five life-prolonging interventions in $\mathrm{mCRPC}^{\mathrm{a}}$

$n(\%)$

$\begin{array}{lcc}0 & 45(21) & 113(26) \\ 1 & 63(29) & 99(23) \\ 2 & 59(27) & 100(23) \\ 3 & 36(16) & 80(18) \\ 4 & 16(7) & 41(9) \\ 5 & 0 & 5(1) \\ \text { Mean number of } & 1.6(1.2) & 1.7(1.3) \\ \text { ACIs (SD) } & & \\ \text { Median number of ACIs } & 2.0(0-4) & 2.0(0-5) \\ \text { (range) } & & \\ \text { Specific post-treatment ACI, } n(\%) & 234(53) \\ \text { Abiraterone } & 123(56) & 184(42) \\ \text { Enzalutamide } & 110(50) & 194(44) \\ \text { Docetaxel } & 80(37) & 96(22) \\ \text { Cabazitaxel } & 36(16) & 20(5) \\ \text { Radium-223 } & 4(2) & \end{array}$

$A C I$ anticancer intervention, $m C R P C$ metastatic castration-resistant prostate cancer, $P S A$ prostate-specific antigen, $S D$ standard deviation.

${ }^{\mathrm{a} A C I s}$ were abiraterone, enzalutamide, docetaxel, cabazitaxel, or radium-223.

differently to systemic therapy with docetaxel, androgen axis inhibitors, or immunotherapy.

Possible mechanisms for greater OS benefit with sipuleucel-T in African Americans are not well understood. One possibility that cannot be confirmed may be that the African American population in PROCEED had relatively more indolent tumor biology, given the longer time to sipuleucel-T therapy initiation. An unlikely possibility for the racial differences in OS observed in PROCEED is the use of subsequent life-prolonging therapies as there was no racial difference in the overall number of survival-prolonging ACIs. Likewise, rates of prior curative local therapy were similar. Use of chemotherapy before sipuleucel-T was higher in Caucasians, despite shorter time from diagnosis to sipuleucel-T treatment. These and other baseline prognostic factors were included in detailed multivariable and sensitivity analyses that found African American race to be independently associated with OS after sipuleucel-T, regardless if looking at the PSA matched cohorts or the all patient cohorts. Residual confounding effects by unmeasured factors (e.g., inflammation, molecular genotypes, number of circulating 
tumor cells, diet, and other host factors) may account for the OS difference and should be considered in future studies.

Sipuleucel-T is designed to activate the immune system against the prostatic acid phosphatase expressed on most prostate cancer cells. Sipuleucel-T-induced antigen-specific cellular and humoral immune responses correlate with OS $[28,29]$. Thus, immunological differences could be one factor leading to greater OS benefit for African Americans with an immunotherapy. Samples to evaluate peripheral immune responses were not collected in PROCEED, preventing confirmation of the potential role of such immune parameters in mediating the observed differences in OS. Consequently, a hypothesis regarding the role of the immune system in mediating the observed OS differences can only be surmised from published literature.

The existing literature appears to support such a hypothesis of racial differences in the immune system and immune responses. Compared with Caucasians, African Americans, including prostate cancer patients [30], have lower neutrophil and monocyte counts and higher lymphocyte counts [31]. Furthermore, genetic differences in white blood cells, related to cellular immune function, have been reported between African Americans and other races [32]. Differences in gene expression also have been observed in immune response pathways in African American men with aggressive prostate cancer [10, 16, 17]. Racial differences also occur in B-cell and T-cell signaling [33, 34]. Moreover, clinical responses and outcomes vary, e.g., greater vaccine-induced humoral immune responses [35] and higher rejection of organ transplants [36] are observed in African Americans than Caucasians, suggesting more robust immune functionality in the former. Thus, it is plausible that an immunotherapy approach, as with sipuleucel-T, may result in greater immune activation in African American men with mCRPC than in Caucasian men. It, however, should be noted that to date the responsiveness of African Americans to other forms of immune therapy is sparsely documented.

Cancer cells in African American men may be more immunogenic. Tumor mutational burden has been compared in African American men with prostate cancer versus Europeans, suggesting that men of African American ethnicity may have more neoepitopes, plausibly leading to more robust antitumor responses versus Caucasians [37]. Future studies that interrogate the role of the immune response in determining clinical outcome after sipuleucel-T are warranted.

In summary, several reports in the literature describe differences between African Americans and Caucasians in both immunology and cancer biology. Taken together, the clinical outcomes observed with sipuleucel-T may in part be due to such differences, including the immune system's innate responsiveness and the effectiveness of immunotherapy at the level of the tumor microenvironment.
Additional research may help elucidate some of these aspects further.

There are several limitations of the current analyses. PROCEED did not include a comparison arm and the analyses performed were exploratory in nature, so the survival differences observed with sipuleucel-T cannot be confirmed in any of the patients. As this was a registry, race was self-reported without ancestral genotyping. Nevertheless, the strengths of the current analysis include the large numbers in the African American cohort, and the consistency in findings of OS improvement among African Americans compared with Caucasians in both the overall and PSA-matched cohorts. African American race also emerged as an independent and strong predictor of OS on multivariable and sensitivity analyses. These data are consistent with the observations of a prior pooled phase III analysis [22]. These observations should motivate new research into immunotherapy responsiveness of African Americans with prostate cancer, with potentially broader implications regarding outcomes among African Americans with other cancers.

\section{Conclusion}

In conclusion, while sipuleucel-T is FDA-approved for men of any race with $\mathrm{mCRPC}$, the PROCEED data suggest that African American men exhibit survival differences compared with Caucasian men when treated with sipuleucel-T, especially at lower PSAs values. Further research is required before this observation is used to drive any potential differential treatment. Rather, the data enhance previous observations as to the utility of sipuleucel-T, including in African American patients with mCRPC. Further research is required to better understand the biologic basis for some of the observed differences between African American and Caucasian men in terms of their responses to immunotherapies and other cancer treatments.

Acknowledgements The investigators and Dendreon thank the patients and study site personnel who contributed to this research. The authors also thank Robert Tyler, formerly of Dendreon Pharmaceuticals LLC, for his contribution to the design and patient recruitment of PROCEED. Medical writing assistance, in the form of development of the draft outline and manuscript first draft in consultation with the authors, revising draft versions of this paper, assembling tables and figures, collating author comments, copy editing, fact checking, referencing, graphic services and submission, was provided by Jackie Phillipson, PhD, of Zoetic Science (Macclesfield, UK) and funded by Dendreon Pharmaceuticals LLC. Additional writing assistance was provided by Helen M Wilfehrt, PhD, ISMPP CMPPTM of Dendreon Pharmaceuticals LLC.

Funding PROCEED was funded by Dendreon Pharmaceuticals LLC. Work conducted at Memorial Sloan Kettering Cancer Center, New York, NY, USA, was funded in part through the NIH/NCI Cancer 
Center Support Grant P30 CA008748. Dendreon Pharmaceuticals LLC funded trial conduct and manuscript development. It was responsible for conceptualization, data curation, data analysis, project/content oversight, and supervision of this research.

\section{Compliance with ethical standards}

Conflict of interest OS served as a consultant for and received personal fees from Advanced Accelerator Applications, Astellas, AstraZeneca, Bavarian-Nordic, Bayer, Bellicum, Blue Earth Diagnostics, BMS, Constellation, Dendreon, EMD Serono, Jenssen, Myriad, Myovant, Noxopharm, Pfizer, Progenics, and Sanofi. Dr. Sartor has also received grants from AstraZeneca, Bayer, Dendreon, Endocyte, Innocrin, Invitae, Jenssen, Merck, NCI, NRG, Sanofi, and Sotio. He is co-chairman of the GU Committee for NRG and a consultant on the board of scientific counselors for NCI. AJA has received grants and personal fees from Dendreon, serving as consultant/advisor, researcher, and speaker. Outside of the submitted work, Dr. Armstrong received grants, personal fees and other support from Bayer as consultant/advisor, researcher, and speaker. Dr. Armstrong received personal fees and other support as honoraria, consultant/advisor, and travel expenses. He also served as a consultant/advisor to Merck, Astra Zeneca, Janssen, and Pfizer/Astellas. His institution Duke received research funding from Bayer, Novartis, Janssen, Gilead Sciences, Roche/Genentech, Bristol-Myers-Squibb, Constellation, Merck, Astra Zeneca, Janssen, and Pfizer/Astellas. CA has nothing to disclose. DGM has nothing to disclose. MRC has received personal fees from Dendreon related to the PROCEED trial steering committee, and served in an advisory or consultancy role for Bayer, Abbvie, and Astra Zeneca. Dr. Cooperberg has also participated in a registry steering committee for Astella. DFP has nothing to declare. PWK has received personal fees from BIND Biosciences, Bavarian Nordic Immunotherapies, DRGT, Janssen, Merck, Metamark, OncoCellMDX, Sanofi, Tarveda Pharmaceuticals, Thermo Fisher, GE Healthcare, Context Therapeutics, New England Research Institutes, SEER Biosciences and Placon. Dr. Kantoff also has investment interests in DRGT, Tarveda Pharmaceuticals, Context Therapeutics, SEER Biosciences and Placon. He is also a board member for Context Therapeutics. NJV has nothing to disclose. AH has nothing to disclose. CMP has received research grants from Dendreon, Bayer, Astellas, Pfizer, LUGPA, Janssen, Astra Zeneca, and Veru. No other relationships present a potential conflict of interest. NDS has nothing to declare. DIQ received research grant/funding from Seattle Genetics, MSD, Novartis, acted as an advisor/consultant for Astellas, Astra Zeneca, Bayer, BMS, Dendreon, Exelixis, Roche, Janssen, MSD, Novartis, Pfizer, Sanofi, and received travel, accommodation and expenses from Pfizer, MSD, Astra Zeneca, BMS, Roche. EJS has received honoraria from Janssen and has served as a consultant or advisory board member for Janssen, Fortis, Beigene, and Tolero. He owns stock in Fortis Therapeutics and Harpoon Therapeutics. EIH received research funding and honoraria, and has served as a consultant for Dendreon. Dr. Heath has also received personal fees and/or non-financial support from Bayer, Sanofi, Seattle Genetics, and Agensys. She received research funding from Tokai Pharmaceuticals, Seattle Genetics, Agensys, Dendreon, Genentech/Roche, Millenium, Caris Life Sciences, Boehringer Ingelheim, Merck Sharp \& Dohme, Plexxicon, Corcept Therapeutics, Fortis, Astellas Pharma, Medivation, AstraZeneca, Ignyta, Synta, Esanik, Zenith Epigenetics, Oncolys BioPharma, Curemeta, BMS, eFFECTOR Therapeutics, Celldex, Inovio Pharmaceuticals, Celgene, and Merck. RFT has nothing to disclose. PFS has nothing to disclose. MH is a full-time employee of Dendreon. NNC was a full-time employee of Dendreon at the time of the analyses and initial drafting of this manuscript. NAS is a full-time employee of Dendreon. BB is a full-time employee of Dendreon. SJF has received personal fees from Dendreon. CSH reports no conflicts of interest related to the work under consideration. Outside of the submitted work, Dr. Higano has participated in sponsored research with Aptevo, Aragon Pharma, Astellas, AstraZeneca, Bayer, Clovis, Dendreon, eFFECTOR Therapeutics, Emergent, Ferring, Genentech, Hoffman-LaRoche, Medivation, and Pfizer. Dr. Higano also has received personal fees for advisory board participation from Aptevo, Asana, Astellas, Bayer, Blue Earth Diagnostics, Churchill Pharma, Clovis Oncology, Dendreon, Endocyte, Ferring, Hinova, Janssen, Myriad, Orion, and Pfizer.

Publisher's note Springer Nature remains neutral with regard to jurisdictional claims in published maps and institutional affiliations.

Open Access This article is licensed under a Creative Commons Attribution 4.0 International License, which permits use, sharing, adaptation, distribution and reproduction in any medium or format, as long as you give appropriate credit to the original author(s) and the source, provide a link to the Creative Commons license, and indicate if changes were made. The images or other third party material in this article are included in the article's Creative Commons license, unless indicated otherwise in a credit line to the material. If material is not included in the article's Creative Commons license and your intended use is not permitted by statutory regulation or exceeds the permitted use, you will need to obtain permission directly from the copyright holder. To view a copy of this license, visit http://creativecommons. org/licenses/by/4.0/.

\section{References}

1. National Comprehensive Cancer Network. NCCN Clinical Practice Guidelines in Prostate Cancer: version 2.2019, April 17, 2019. National Comprehensive Cancer Network, 2019, pp. NCCN Clinical Practice Guidelines in Oncology (NCCN Guidelines $\left.{ }^{\circ}\right)$ Prostate Cancer (Version 2.2019, April 2017, 2019).

2. Kantoff PW, Higano CS, Shore ND, Berger ER, Small EJ, Penson DF, et al. Sipuleucel-T immunotherapy for castration-resistant prostate cancer. N Engl J Med. 2010;363:411-22. https://doi.org/ 10.1056/NEJMoa1001294

3. Schellhammer PF, Chodak G, Whitmore JB, Sims R, Frohlich MW, Kantoff PW. Lower baseline prostate-specific antigen is associated with a greater overall survival benefit from sipuleucel-T in the Immunotherapy for Prostate Adenocarcinoma Treatment (IMPACT) trial. Urology. 2013;81:1297-302. https://doi.org/10. 1016/j.urology.2013.01.061

4. Higano CS, Armstrong AJ, Sartor AO, Vogelzang NJ, Kantoff PW, McLeod DG, et al. Real-world outcomes of sipuleucel-T treatment in PROCEED, a prospective registry of men with metastatic castration-resistant prostate cancer. Cancer. 2019;125:4172-80. https://doi.org/10.1002/cncr.32445

5. Smith ZL, Eggener SE, Murphy AB. African-American prostate cancer disparities. Curr Urol Rep. 2017;18:81. https://doi.org/10. 1007/s11934-017-0724-5

6. Bhardwaj A, Srivastava SK, Khan MA, Prajapati VK, Singh S, Carter JE, et al. Racial disparities in prostate cancer: a molecular perspective. Front Biosci (Landmark Ed). 2017;22:772-82. https://doi.org/10.2741/4515

7. Chornokur G, Dalton K, Borysova ME, Kumar NB. Disparities at presentation, diagnosis, treatment, and survival in African American men, affected by prostate cancer. Prostate. 2011;71:985-97. https://doi.org/10.1002/pros.21314

8. Ahaghotu C, Tyler R, Sartor O. African American participation in oncology clinical trials-focus on prostate cancer: implications, 
barriers, and potential solutions. Clin Genitourin Cancer. 2016;14:105-16. https://doi.org/10.1016/j.clgc.2015.12.003

9. Wallace TA, Prueitt RL, Yi M, Howe TM, Gillespie JW, Yfantis HG, et al. Tumor immunobiological differences in prostate cancer between African-American and European-American men. Cancer Res. 2008;68:927-36. https://doi.org/10.1158/0008-5472.CAN07-2608

10. Kinseth MA, Jia Z, Rahmatpanah F, Sawyers A, Sutton M, WangRodriguez J, et al. Expression differences between African American and Caucasian prostate cancer tissue reveals that stroma is the site of aggressive changes. Int J Cancer. 2014;134:81-91. https://doi.org/10.1002/ijc.28326

11. Yamoah K, Johnson MH, Choeurng V, Faisal FA, Yousefi K, Haddad Z, et al. Novel biomarker signature that may predict aggressive disease in African American men with prostate cancer. J Clin Oncol. 2015;33:2789-96. https://doi.org/10.1200/JCO. 2014.59.8912

12. Powell IJ, Dyson G, Land S, Ruterbusch J, Bock CH, Lenk S, et al. Genes associated with prostate cancer are differentially expressed in African American and European American men. Cancer Epidemiol Biomark Prev. 2013;22:891-7. https://doi.org/ 10.1158/1055-9965.epi-12-1238

13. Huang FW, Mosquera JM, Garofalo A, Oh C, Baco M, AminMansour A, et al. Exome sequencing of African-American prostate cancer reveals loss-of-function ERF mutations. Cancer Discov. 2017;7:973-83. https://doi.org/10.1158/2159-8290.cd-160960

14. Wang BD, Ceniccola K, Hwang S, Andrawis R, Horvath A, Freedman JA, et al. Alternative splicing promotes tumour aggressiveness and drug resistance in African American prostate cancer. Nat Comm. 2017;8:15921. https://doi.org/10.1038/ ncomms 15921

15. DeSantis CE, Miller KD, Goding Sauer A, Jemal A, Siegel RL. Cancer statistics for African Americans, 2019. CA Cancer J Clin. 2019;69:211-33. https://doi.org/10.3322/caac.21555

16. Rebbeck TR, Devesa SS, Chang BL, Bunker CH, Cheng I, Cooney $\mathrm{K}$, et al. Global patterns of prostate cancer incidence, aggressiveness, and mortality in men of african descent. Prostate Cancer. 2013;2013:560857. https://doi.org/10.1155/2013/560857

17. Powell IJ, Bock CH, Ruterbusch JJ, Sakr W. Evidence supports a faster growth rate and/or earlier transformation to clinically significant prostate cancer in black than in White American men, and influences racial progression and mortality disparity. J Urol. 2010;183:1792-7. https://doi.org/10.1016/j.juro.2010.01.015

18. Halabi S, Vogelzang NJ, Ou SS, Kelly WK, Small EJ. Clinical outcomes by age in men with hormone refractory prostate cancer: a pooled analysis of 8 Cancer and Leukemia Group B (CALGB) studies. J Urol. 2006;176:81-86. https://doi.org/10.1016/S00225347(06)00566-0

19. Halabi S, Dutta S, Tangen CM, Rosenthal M, Petrylak DP, Thompson IM, et al. Overall survival of Black and White men with metastatic castration-resistant prostate cancer treated with docetaxel. J Clin Oncol. 2018;37:403-10. https://doi.org/10.1200/ JCO.18.01279

20. Zhao H, Howard L, De Hoedt A, Terris MK, Amling C, Kane C, et al. Racial discrepancies in overall survival among men treated with radium-223. J Urol. 2019. https://doi.org/10.1097/JU. 0000000000000524 .

21. McNamara MA, George DJ, Ramaswamy K, Lechpammer S, Mardekian J, Schultz NM, et al. Overall survival by race in chemotherapy-naïve metastatic castration-resistant prostate cancer (mCRPC) patients treated with abiraterone acetate or enzalutamide. J Clin Oncol. 2019;37:212. https://doi.org/10.1200/JCO. 2019.37.7_suppl.212

22. McLeod DG, Quinn DI, Cullen J, Whitmore JB. 953 Sipuleucel-T in African-Americans: a subgroup analysis of three phase
3 studies of sipuleucel-T in metastatic castrate-resistant prostate cancer. J Urol. 2012;187:e388. https://doi.org/10.1016/j.juro. 2012.02.1051

23. Higano CS, Schellhammer PF, Small EJ, Burch PA, Nemunaitis J, Yuh L, et al. Integrated data from 2 randomized, double-blind, placebo-controlled, phase 3 trials of active cellular immunotherapy with sipuleucel-T in advanced prostate cancer. Cancer. 2009;115:3670-9. https://doi.org/10.1002/cncr.24429

24. Small EJ, Schellhammer PF, Higano CS, Redfern CH, Nemunaitis JJ, Valone FH, et al. Placebo-controlled phase III trial of immunologic therapy with sipuleucel-T (APC8015) in patients with metastatic, asymptomatic hormone refractory prostate cancer. J Clin Oncol. 2006;24:3089-94. https://doi.org/10.1200/JCO.2005. 04.5252

25. Higano CS, Armstrong AJ, Sartor AO, Vogelzang NJ, Kantoff PW, McLeod DG, et al. Cerebrovascular event (CVE) outcome and overall survival (OS) in patients (pts) treated with sipuleucel$\mathrm{T}$ (sip-T) for metastatic castration-resistant prostate cancer (mCRPC): results from the PROCEED registry. J Clin Oncol. 2018;36:Abstract e17018.

26. Small EJ, Fratesi P, Reese DM, Strang G, Laus R, Peshwa MV, et al. Immunotherapy of hormone-refractory prostate cancer with antigen-loaded dendritic cells. J Clin Oncol. 2000;18:3894-903. https://doi.org/10.1200/JCO.2000.18.23.3894

27. Spratt DE, Osborne JR. Disparities in castration-resistant prostate cancer trials. J Clin Oncol. 2015;33:1101-3. https://doi.org/10. 1200/JCO.2014.58.1751

28. Sheikh NA, Petrylak D, Kantoff PW, Dela Rosa C, Stewart FP, Kuan LY. Sipuleucel-T immune parameters correlate with survival: an analysis of the randomized phase 3 clinical trials in men with castration-resistant prostate cancer. Cancer Immunol Immunother. 2013;62:137-47. https://doi.org/10.1007/s00262$012-1317-2$

29. Antonarakis ES, Small EJ, Petrylak DP, Quinn DI, Kibel AS, Chang NN, et al. Antigen-specific CD8 lytic phenotype induced by sipuleucel-T in hormone-sensitive or castration-resistant prostate cancer and association with overall survival. Clin Cancer Res. 2018;24:4662 https://doi.org/10.1158/1078-0432.CCR$18-0638$

30. Vidal AC, Howard LE, de Hoedt A, Cooperberg MR, Kane CJ, Aronson WJ, et al. Neutrophil, lymphocyte and platelet counts, and risk of prostate cancer outcomes in white and black men: results from the SEARCH database. Cancer Causes Control. 2018;29:581-8.

31. Lim EM, Cembrowski G, Cembrowski M, Clarke G. Race-specific WBC and neutrophil count reference intervals. Int J Lab Hematol. 2010;32:590-7.

32. Keller MF, Reiner AP, Okada Y, van Rooij FJA, Johnson AD, Chen M-H, et al. Trans-ethnic meta-analysis of white blood cell phenotypes. Hum Mol Genet. 2014;23:6944-60.

33. Longo DM, Louie B, Mathi K, Pos Z, Wang E, Hawtin RE, et al. Racial differences in $\mathrm{B}$ cell receptor signaling pathway activation. J Transl Med. 2012;10:113. https://doi.org/10.1186/ 1479-5876-10-113

34. Sugimoto K, Stadanlick J, Ikeda F, Brensinger C, Furth EE, Alter $\mathrm{HJ}$, et al. Influence of ethnicity in the outcome of hepatitis $\mathrm{C}$ virus infection and cellular immune response. Hepatology. 2003;37:590-9. https://doi.org/10.1053/jhep.2003.50103

35. Kurupati R, Kossenkov A, Haut L, Kannan S, Xiang Z, Li Y, et al. Race-related differences in antibody responses to the inactivated influenza vaccine are linked to distinct pre-vaccination gene expression profiles in blood. Oncotarget. 2016;7:62898-911. https://doi.org/10.18632/oncotarget.11704

36. Morris AA, Cole RT, Veledar E, Bellam N, Laskar SR, Smith AL, et al. Influence of race/ethnic differences in pre-transplantation panel reactive antibody on outcomes in heart transplant recipients. 
J Am Coll Cardiol. 2013;62:2308-15. https://doi.org/10.1016/j.ja cc.2013.06.054

37. Jaratlerdsiri W, Chan EKF, Gong T, Petersen DC, Kalsbeek AMF, Venter PA, et al. Whole-genome sequencing reveals elevated tumor mutational burden and initiating driver mutations in African men with treatment-naïve, high-risk prostate cancer. Cancer Res. 2018;78:6736. https://doi.org/10.1158/0008-5472.CAN-18-0254

\section{Affiliations}

Oliver Sartor ${ }^{1} \cdot$ Andrew J. Armstrong $\mathbb{D}^{2} \cdot$ Chiledum Ahaghotu $^{3} \cdot$ David G. McLeod $^{4,5} \cdot$ Matthew R. Cooperberg $\mathbb{B}^{6}$. David F. Penson ${ }^{7}$. Philip W. Kantoff ${ }^{8} \cdot$ Nicholas J. Vogelzang $^{9} \cdot$ Arif Hussain $^{10}$. Christopher M. Pieczonka ${ }^{11}$. Neal D. Shore ${ }^{12}$ - David I. Quinn ${ }^{13} \cdot$ Eric J. Small $^{14}$ - Elisabeth I. Heath ${ }^{15} \cdot$ Ronald F. Tutrone $^{16}$. Paul F. Schellhammer ${ }^{17} \cdot$ Matthew Harmon $^{18} \cdot$ Nancy N. Chang ${ }^{18} \cdot$ Nadeem A. Sheikh $^{18} \cdot$ Bruce Brown $^{18}$. Stephen J. Freedland ${ }^{19,20} \cdot$ Celestia S. Higano ${ }^{21}$

Tulane Medical School, New Orleans, LA, USA

2 Duke Prostate and Urologic Cancer Center, Duke Cancer Institute, Durham, NC, USA

3 MedStar Southern Maryland Hospital Center, Maryland, MD, USA

4 Center for Prostate Disease Research at the Uniformed Services University of Health Sciences, Bethesda, MD, USA

5 The Walter Reed National Military Medical Center, Bethesda, MD, USA

6 Departments of Urology and Epidemiology and Biostatistics, University of California San Francisco, San Francisco, CA, USA

7 Vanderbilt University Medical Center, Nashville, TN, USA

8 Memorial Sloan Kettering Cancer Center, New York, NY, USA

9 Comprehensive Cancer Centers of Nevada, Las Vegas, NV, USA

10 University of Maryland School of Medicine, Baltimore, MD, USA

11 Associated Medical Professionals, Syracuse, NY, USA
12 Department of Urology, Carolina Urologic Research Center, Myrtle Beach, SC, USA

13 Norris Comprehensive Cancer Center, University of Southern California, Los Angeles, CA, USA

14 UCSF Helen Diller Family Comprehensive Cancer Center, University of California San Francisco, San Francisco, CA, USA

15 Karmanos Cancer Institute, Wayne State University School of Medicine, Detroit, MI, USA

16 Chesapeake Urology Research Associates, Towson, MD, USA

17 Department of Urology, Eastern Virginia Medical School Urology of Virginia, Virginia, VA, USA

18 Dendreon Pharmaceuticals LLC, Seattle, WA, USA

19 Center for Integrated Research in Cancer and Lifestyle, Cedars-Sinai Medical Center, Los Angeles, CA, USA

20 The Durham Veterans Administration, Durham, NC, USA

21 University of Washington and Fred Hutchinson Cancer Research Center, Seattle, WA, USA 